\title{
Estimation of Concentration of Dissolved Organic Matter from Sediment by using UV-Visible Spectrophotometer
}

\author{
Shamshad Khan', Wu Yaoguo', Zhang Xiaoyan', Liu Jingtao², Sun Jichao², Hu Sihai' \\ ${ }^{1}$ Department of Applied Chemistry, School of Science, \\ Northwestern Polytechnical University, Xi'an, 710072, China \\ shamshadkhan768@yahoo.com;wuygal@nwpu.edu.cn \\ ${ }^{2}$ The Institute of Hydrogeology and Environmental Geology, Shijiazhuang, 050803, China
}

\begin{abstract}
The objective of this research was to develop a spectrophotometric technique for estimation of concentration of dissolved organic matter (DOM) from sediment. The results showed that the absorbance $272 \mathrm{~nm}$ is good surrogate to the concentration of the DOM. In addition, absorption of DOM confirmed to be independent of $\mathrm{pH}$ values ranging from 3.0 to 11. Compare to the chemical oxygen demand method and TOC-analyzer, the develop correlation technique using the UVvisible absorption is very straightforward, needs much smaller sample volume, and shows a good reproducibility. The absorbance $(272 \mathrm{~nm})$ increased with increasing the concentrations of DOM with very high correlation coefficient $\left(R^{2}=0.98\right)$. So it is suggested that this technique should be used as a surrogate for estimation of concentration of DOM from sediment.
\end{abstract}

Keywords: absorbance, surrogate, sediment, dissolved organic matter, concentration.

CCopyright 2014 Authors - This is an Open Access article published under the Creative Commons Attribution License terms http://creativecommons.org/licenses/by/3.0. Unrestricted use, distribution, and reproduction in any medium are permitted, provided the original work is properly cited.

\section{Introduction}

The importance of dissolved organic matter (DOM) as a key parameter in environmental studies is well understood. Dissolved organic matter is involved in mobilization, complexation of trace metals and transport of acidity, colloids, nutrients, metals, and pollutants [1, 2]. Dissolved organic matter act as an originator of carcinogenic disinfection by-products (DBPs) such as trihalomethanes (THMs) and haloacetic acids (HAAs) increased disinfectant demands in the distribution system [3-7] has been extensively studied for the protection of public health. These various interactions with the environment result from the fact that it represents a complex mixture of substances with chemical structure and different size. Therefore, the significance of DOM in the environment is very much associated to its composition.

Even if many studies have been accomplished to reduce the effects of DOM in water treatment, not many literatures are available for the characterization of DOM [8-12]. Therefore, the composition of DOM has been studied by various techniques including spectroscopic measurements, and physical and chemical fractionation, often in combination [1]. Result of these studies is that humic acids are the major part of DOM which includes carbonyl, carboxylic, hydroxyl, methoxyl, and phenolic functional groups. Primary composition for humic acids is carbon (52-56\%), hydrogen (4-5.5\%), oxygen (33$39 \%$ ), and small percentages of nitrogen, sulfur, and phosphorus [13]. Based on the degradation products after alkaline hydrolysis and permanganate oxidation, Christman et al. [11] were able to suggest hypothetical structures for humic acids. However, it is for now impossible to observe the complete specific structure of DOM due to its complex structure. At this time, two analytical indirect techniques are commonly available to estimate the concentration of DOM. Total organic carbon (TOC) and UV absorbance measured at $254 \mathrm{~nm}$ are used as substitute to evaluate the DOM concentration. Total organic carbon (TOC) and UV absorbance $(254 \mathrm{~nm})$ estimate organic carbon content 
in the water and are used as a proxy to represent the DOM concentration and in particular, of THMs precursor material [14,15]. It was reported that correlation between UV absorbance at $254 \mathrm{~nm}$ and disinfection by-products (DBPs) formation potential give a better estimation of organic matter reactivity than TOC $[13,16]$. But the limitation of this technique is also found in literature [17]. The value of absorbance $(254 \mathrm{~nm})$ particularly depends on the concentrations of humic acids in water. UV absorbance $(254 \mathrm{~nm})$ value of humic acids reduces by chlorination due to formation of organic halogen. When the concentration of humic acids is low, the UV254 acquired may be too low and generate a comparatively high random error [3].

Usually, the DOM in water produces an uncharacteristic spectrum by absorbing the ultraviolet light $200 \mathrm{~nm}$ to $700 \mathrm{~nm}$ with no sharp peaks [8] and the absorbance decreases as the wavelength increases. There is no visible variation between the spectra for humic and fulvic acids. It has been shown that no maximum or minimum peaks are present on the ultraviolet spectra of the aqueous solution of humic acids [8] and the optical absorbance reduces as the wavelength increases. Although the DOM with different sources may have different configurations and their chemical properties, their spectra are similar. Aromatic moieties parts in DOM offer the possibility to guess the proportion of dissolved organic carbon in DOM using UV-Visible spectrophotometer because UV absorption of organic solutes is directly proportional to their concentration in aromatic compounds $[18,19]$. This correlation demonstrated that the direct measurement of the UV absorbance gives suitable and valuable information for the characterization of the DOM in water. Wang and Hsieh [3] established a correlation between the absorbance spectrum of different wavelengths $(250-350 \mathrm{~nm})$ and the concentration in natural organic matter. It is seems probable that a significant relationship could be developed between dissolved organic matter and absorbance at any wavelengths between $200 \mathrm{~nm}$ and middle of visible range.

Based on the above discussions, the absorbance of DOM solutions at various wavelengths should be able to represent the concentrations of some specific constituents of DOM sample. Thus the objectives of this study are to establish the most favorable wavelength range that provides optimum predictabitly of dissolved organic matter from absorbance and the particular wavelength that should be able to represent the concentration of some particular components of the DOM. In addition we will analysis the effect of $\mathrm{pH}$ on the UV-visible spectra of DOM.

\section{Material and Methods}

A sediment sample was collected from the topsoil $(0-15 \mathrm{~cm})$ of Weihe riverbed in Xi'an, China. Sediment sample was air-dried, grounded, sieved to $<2 \mathrm{~mm}$ and stored in a plastic bottle until used. Selected physiochemical properties of sediment sample are shown in Table 1. Cation exchange capacity (CEC) of sediment was measured at $\mathrm{pH} 7.0$ using $1 \mathrm{~mol} \mathrm{~L}^{-1}$ ammonium acetate. The natural $\mathrm{pH}$ of sediment was measured in a 1:10 material/water ratio by $\mathrm{pH}$ meter (PHS-3C, Leici, Shanghai, China). Specific surface area (SSA) and micro porosity were evaluated by $\mathrm{N}_{2}$-BET method (Tristar II 3020, Micromeritics, USA). Elemental composition was measured by energy dispersive spectrometer (INCA X-Act, TESCAN, Cezch). Soil organic carbon (SOC) content was determined by the wet dichromate oxidation method.

Table 1. Basic physicochemical properties of tested sediment.

\begin{tabular}{|c|c|c|c|c|c|c|c|c|}
\hline $\mathrm{pH}$ & $\begin{array}{l}\text { CEC } \\
\text { (cmol.kg-1) }^{-1}\end{array}$ & $\begin{array}{l}\text { SSA } \\
\mathrm{m}^{2} \mathrm{~g}^{-1}\end{array}$ & $\begin{array}{l}\text { Pore } \\
\text { Size } \\
(\mathrm{nm})\end{array}$ & SOC & C & Ca & $\mathrm{Al}$ & $\mathrm{Fe}$ \\
\hline 8.0 & 10.54 & 7.23 & 92.32 & 4.79 & 2.80 & 3.98 & 5.64 & 3.57 \\
\hline
\end{tabular}

This sediment was used as source of DOM in water. Extraction of DOM was carried out just before absorption experiments by adding $200 \mathrm{ml}$ deionized water to 6gram of sediment in a plastic bottle and shaking for $24 \mathrm{~h}$ on an orbital shaker at $(20 \pm 1){ }^{\circ} \mathrm{C}$. After that, the suspension was centrifuged at $900 \times \mathrm{g}$ for 30 min and filtered through $0.45-\mu \mathrm{m}$ pore size polycarbonate filter. Total organic carbon was determined by total organic carbon analyzer (TOC-VVSH, Shimadzu, Tokyo, Japan). The non-purgable organic carbon (NPOC) technique was used to measure TOC (organic carbon remaining in an acidified sample after purging the sample with gas). The result TOC was calculated as a mean of the three valid measurements. Stock solution of $70 \mathrm{mg} \mathrm{L}^{-1}$ of DOM was used to prepare six different concentrations of diluted solutions of DOM. UV-visible absorbance measurements were performed on a high precision, double-beam spectrophotometer (model 2550) between 220 and $600 \mathrm{~nm}$ with the reference of distilled water. A quartz cell with $1.0 \mathrm{~cm}$ 
path length was used. Samples were allowed to warm to room temperature before measurement. Duplicates and measurement of the distilled water were made every 10-12 samples to ensure instrument stability. Buffer solution to maintain $\mathrm{pH}$ were not required because solutions were prepared at different $\mathrm{pH}$ have showed that UV-visible spectra were not notably affected by the 3 to 11 range of $\mathrm{pH}$ as shown in Figure 1.

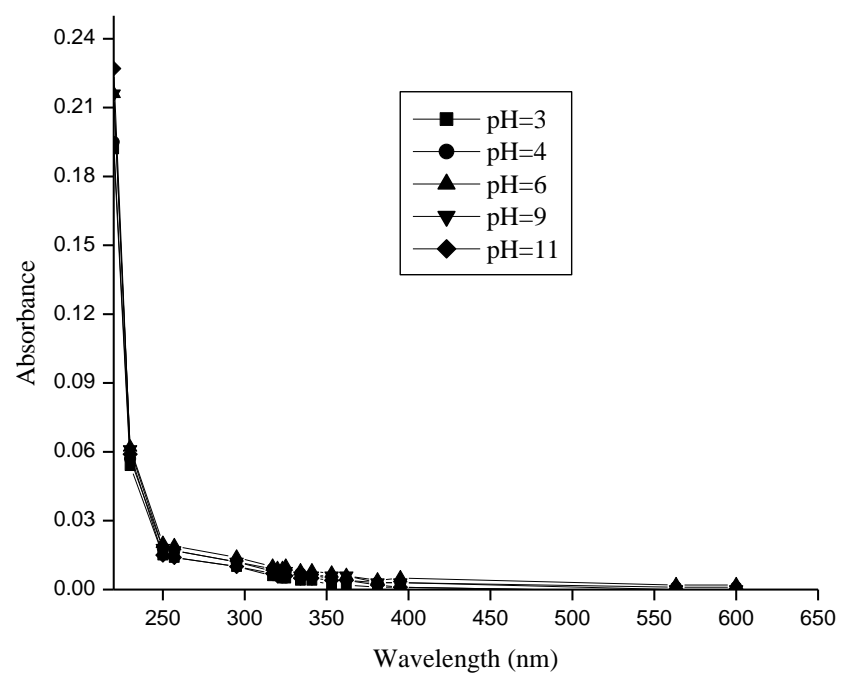

Figure 1. Effect of pH on UV-visible spectra of dissolved organic matter in water from sediment.

\section{Results and Discussion}

For selection of appropriate wavelength to the concentration of DOM and absorbance in water, various concentrations $(9.1,11.5,13.9,16.3,18.7,21.1,23.5 \mathrm{mg}$ $\mathrm{L}^{-1}$ ) of DOM. Figure 2 illustrates that the absorbance of DOM increases as the concentrations increase. The absorbance at wavelength length less than $250 \mathrm{~nm}$ is much larger than of longer wavelength. As a result, a sharp slope is observed at the shorter wavelength $(<275 \mathrm{~nm})$, this phenomenon is much more visible when the concentration of DOM is high. The absorbance measured at greater wavelength $(>360 \mathrm{~nm})$ is relatively less than absorbance at $250-360 \mathrm{~nm}$. This result is approximately in agreement with the experimental results of Wang and Hsieh [3].

As can be seen in figure 2, absorbance values less than $250 \mathrm{~nm}$ were not included in the study because of the strong absorbance by nitrates. Wavelength greater than $360 \mathrm{~nm}$ is also not included due to the insensitivity of absorbance to changes in DOM at longer wavelength. As a consequence the correlation between absorbance and DOM data are restricted to the $250-360 \mathrm{~nm}$ range.

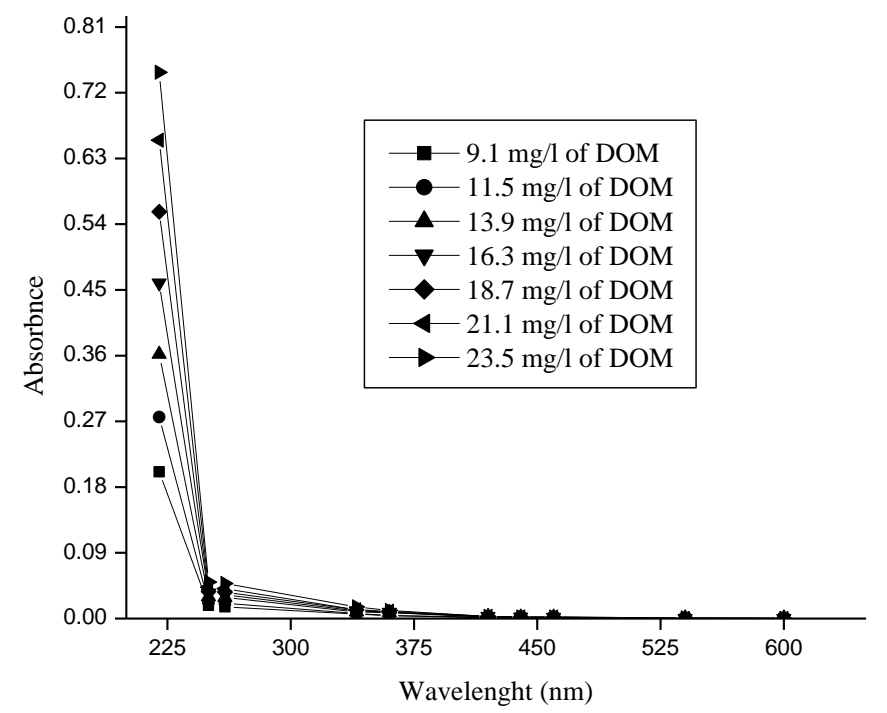

Figure 2. UV-visible spectra of different concentrations of dissolved organic matter in water from sediment.

For the estimation of the most favorable wavelength ranges between $250 \mathrm{~nm}$ and $360 \mathrm{~nm}$, it is possible to add all the data to correlation regression analysis by considering the $10 \mathrm{~nm}$ part length of restricted wavelength range $250-360 \mathrm{~nm}$. Correlation coefficient $\left(\mathrm{R}^{2}\right)$ was determined for each part length of $10 \mathrm{~nm}$ of the restricted wavelength range $250-360 \mathrm{~nm}$. The highest correlation coefficient $\left(\mathrm{R}^{2}=0.97\right)$ was obtained between range of $270 \mathrm{~nm}$ and $280 \mathrm{~nm}$. Figure 3 shows the correlation of DOM and selected wavelengths range $(250-360 \mathrm{~nm})$ of $23.5 \mathrm{~mL}$ solution of DOM. The maximum linear correlation coefficient $\left(\mathrm{R}^{2}=0.97\right)$ obtained at wavelength range 270 and $280 \mathrm{~nm}$ by analysis of all the data of between $250 \mathrm{~nm}$ and $360 \mathrm{~nm}$. The most favorable correlation coefficient $\left(\mathrm{R}^{2}=0.97\right)$ was obtained between the 270 and $280 \mathrm{~nm}$. (The correlation coefficient lower than $270 \mathrm{~nm}$ and higher $280 \mathrm{~nm}$ are not shown here due to insignificant values). There is steady decline in the correlation coefficient below $270 \mathrm{~nm}$ is probably due to growing amount of interferences by organic compounds of dissimilar classes. Drastic decline in correlation coefficient at higher wavelengths $(>280 \mathrm{~nm})$ that is possibly due to declining the sensitivity of absorbance to the presence of organic compounds. It thus illustrates that DOM is mostly closely associated to absorbance in the wavelength range $270-280 \mathrm{~nm}$. The correlation coefficients propose that the ideal analytical wavelength is between 270 and $280 \mathrm{~nm}$. 


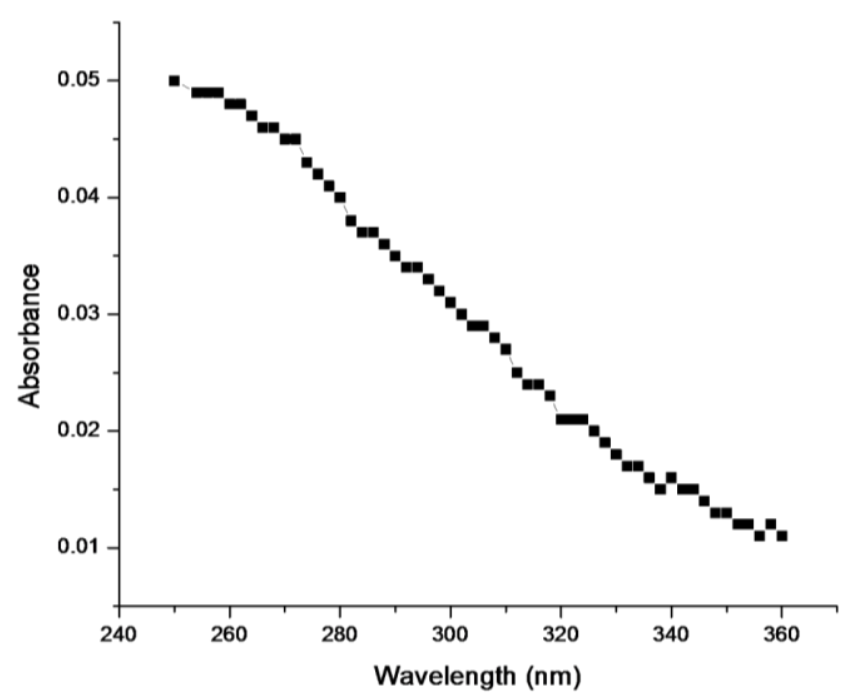

Figure 3. Relation between absorbance and concentration of dissolved organic matter as function of wavelengths.

For the selection of most favorable wavelength between the wavelength range $270-280 \mathrm{~nm}$, correlation coefficients were examined at interval of $2 \mathrm{~nm}$ in the wavelength range $270-280 \mathrm{~nm}$ while increasing the concentrations of DOM solutions. The optimum correlation coefficient $\left(\mathrm{R}^{2}=0.98\right)$ was obtained at the specific wavelength $272 \mathrm{~nm}$ between the wavelength range 270-280nm (data not shown). For the verification of this technique, we developed a relationship between the absorbance $(272 \mathrm{~nm})$ and the different concentrations of DOM determined by TOC carbon analyzer.

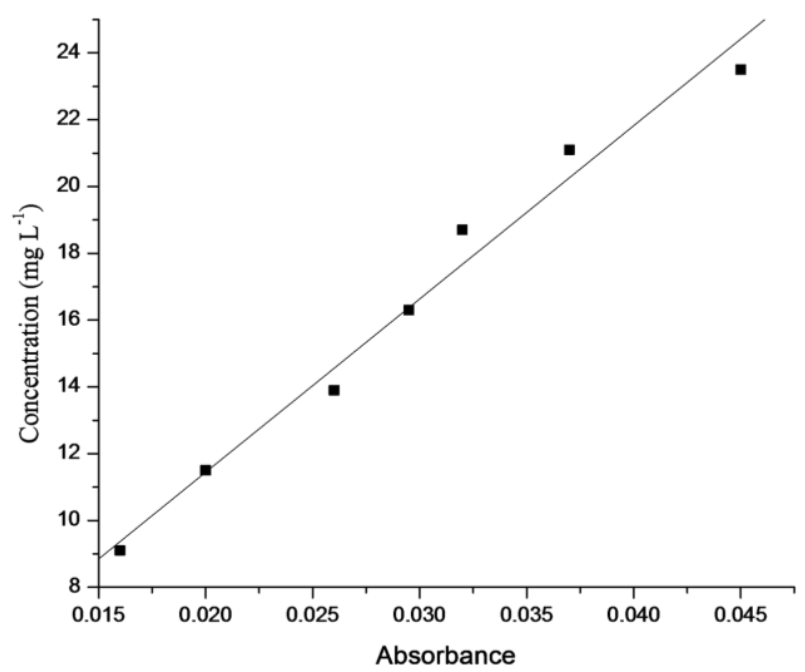

Figure 4. Correlation between absorbance at $272 \mathrm{~nm}$ and concentration of dissolved organic matter in water from sediment determined by TOC carbon analyzer method.
Figure 4 shows the correlation between the absorbance $(272 \mathrm{~nm})$ and the concentration of DOM of sediment in water. Absorbance at $272 \mathrm{~nm}$ is highly related $\left(\mathrm{R}^{2}>0.98 ; \mathrm{P}<0.0001\right)$ to the concentration of DOM determined by TOC carbon analyzer. It is recommended that the absorbance at $272 \mathrm{~nm}$ should be used to estimate the concentration of DOM in sediments.

$$
\begin{aligned}
& \mathrm{DOM}(\mathrm{mg} / \mathrm{l})= \\
& 518.93 \times \text { Absorbance }(272 \mathrm{~nm})+1.065
\end{aligned}
$$

In the above equation $1,518.93$ and 1.065 are the slope and y-intercept respectively. The intercept of the regression line illustrate the presence of $1.065 \mathrm{mg} \mathrm{L}^{-1}$ of non-UV absorbing DOM, probably due to the organic matter containing no chromophores absorbing at $272 \mathrm{~nm}$. This DOM could contain carbohydrates, saturated aliphatic compounds. Data presented in Figure 5 compare the values of concentrations of DOM estimated by TOC carbon analyzer and UV-visible spectrophotometer at $272 \mathrm{~nm}$. A strong linear correlation $\left(\mathrm{R}^{2}=0.99\right)$ exists between these two methods.

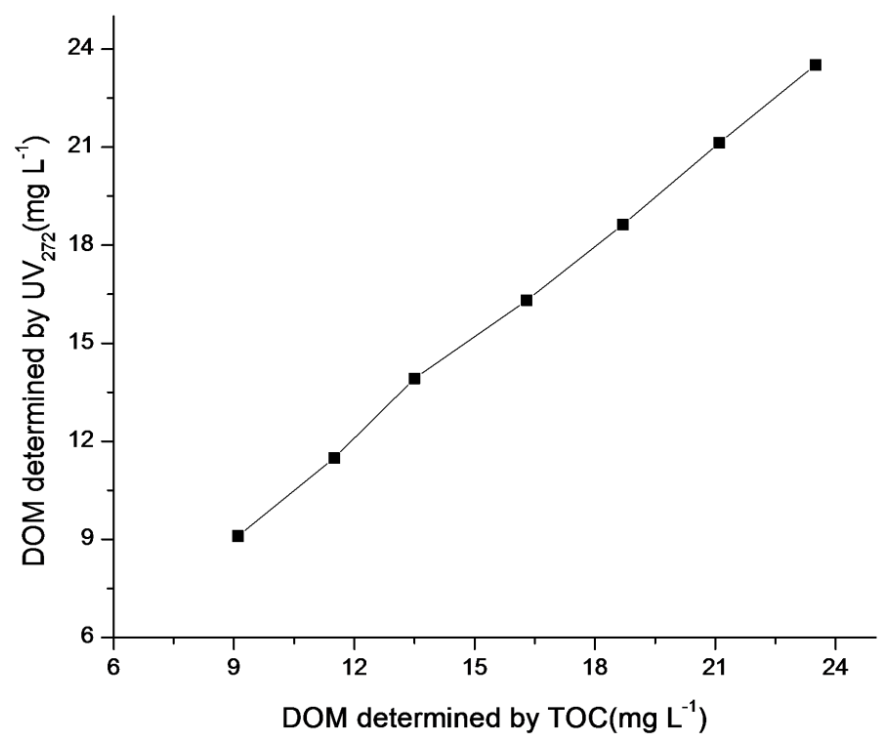

Figure 5. Correlation of the concentrations of DOM by $\mathrm{UV}_{272}$ method versus concentrations of DOM determined by the TOC carbon analyzer.

The higher correlation relationship of DOM with absorbance demonstrates that this technique should be used for assessment of concentration of DOM and it is very suitable and economical for estimation of DOM in water from sediment. Because other techniques like 
Chemical oxygen method and TOC analyzer techniques are more time consuming, expensive, and need more sophisticated instruments, this method is interesting because it only requires a UV-visible spectrophotometer. Another benefit is that in normal working range of $\mathrm{pH}$ no need to use buffer solution because changes of $\mathrm{pH}$ within normal working ranges has no effect on this technique.

\section{Conclusion}

The most favorable correlation coefficient $\left(\mathrm{R}^{2}=\right.$ 0.98 ) wavelength range is obtained among $270 \mathrm{~nm}$ and $280 \mathrm{~nm}$ by adding all the data to correlation regression analysis. There is high correlation coefficient $\left(\mathrm{R}^{2}=0.98\right)$ at specific wavelength $272 \mathrm{~nm}$ between the wavelength (270-280nm) and absorbance by using UV-visible spectrophotometer. The correlations of DOM with absorbance indicate that this method should be used for estimation of concentration of DOM in water form sediment. This method has benefit over general techniques for estimation of DOM concentrations with less time consumption. It is also valuable in normal working $\mathrm{pH}$ range (3-11).

\section{Acknowledgements}

This work was supported by the Land and Resources Scientific Research of China from special fund (20111020) in the public interest, the project titled "survey and assessment of groundwater pollution in main cities of Northwestern China (1212011220982)" and "NPU Foundation for Fundamental Research (NPU-FFR-JCR20130145)”.

\section{References}

[1]J. Dilling, K. Kaiser "Estimation of the hydrophobic fraction of dissolved organic matter in water samples using UV photometry" Water Research, 36(20), 2002, pp. 5037-5044.

[2] K. Shamshad, W. Yaoguo, Z. Xiaoyan, H. Sihai, L. Tao, F. Yilin, L. Qiuge "Influence of dissolved organic matter from corn straw on $\mathrm{Zn}$ and $\mathrm{Cu}$ sorption to Chinese loess" Toxicological \& Environmental Chemistry, 95(8), 2013, pp. 1318-1327.

[3] G.S. Wang, S.T. Hsieh "Monitoring natural organic matter in water with scanning spectrophotometer" Environment International, 26(4), 2001, pp. 205212.

[4]H.O. Neung, A.P. Brian, A.M. Philip, J.H. Peter, M.B. Sandra, O. Noriaki, M.L. Kavvas, A.B. Brian, R.H. William "The role of irrigation runoff and winter rainfall on dissolved organic carbon loads in an agricultural watershed" Agriculture, Ecosystems and Environment, 179(1), 2013, pp.1- 10.

[5]E.R. Newall, F.D. Hulot, J.L. Janeau, A. Merroune "CDOM fluorescence as a proxy of DOC concentration in natural waters: a comparison of four contrasting tropical systems" Environmental Monitoring and Assessment, 186(1), 2014, pp.589-596.

[6]G. Rachel, J.H. Peter, W. Naomi, F. Christopher "Dissolved organic carbon and trihalomethane precursor removal at a UK upland water treatment works" Science of the Total Environment. 468469(1), 2014, pp.228-239.

[7] A.L. Bonnie, M.C. Rose, S.W. Howard "Changes in dissolved organic matter fluorescence and disinfectionbyproduct formation from UV and subsequent chlorination/chloramination" Journal of Hazardous Materials, 264(1), 2014, pp. 411- 419.

[8] G. Crozes, P. White, M. Marshall "Enhanced coagulation: its effect on NOM removal and chemical costs" Journal American Water Works Association, 87(1), 1995, pp. 78-89.

[9] J.G. Jacangelo, J. Demarco, D.M. Owen, S.J. Randtke "Selected processes for removing NOM: an overview: Natural organic matter" Journal American Water Works Association, 87(1), 1995, pp. 64-77.

[10] S.J. Randtke "Organic contaminant removal by coagulation and related processes combinations" Journal American Water Works Association, 80(5), 1988, pp. 40-56.

[11] R.F. Christman, D.L. Norwood, Y. Seo, F.H. Frimmel "Humic substances: II. In search of structure" In: Hayes, M.H.B., Mac-Carty, P., Malcolm, R.L., Swift, R.S. (eds).Publishing Wiley, Chichester, England, 1985, pp. 451-463.

[12] G.G. Choudhry "Humic substances, structural, photophysical, photochemical and free radical aspects and interactions with environmental chemicals" Gordon \& Breach, New York, 1984, pp. 98-106.

[13] D.A. Reckhow, P.C. Singer, R.L. Malcolm "Chlorination of humic materials: byproduct formation and chemical interpretations" Environmental Science \& technology, 24(11), 1990, pp. $1655-1664$.

[14] I.N. Najm, N.L. Patania, J.G. Jacangelo, S.W. Krasner "Evaluating surrogates for disinfection byproducts" Journal American Water Works Association, 86(6), 1994, pp.98-106. 
[15] A. Eaton "Measuring UV-absorbing organics: a standard method" Journal American Water Works Association, 87(2), 1995, pp.86-90.

[16] P. Roccaro, F.G.A. Vagliasindi "Differential vs. absolute UV absorbance approaches in studying NOM reactivity in DBPs formation: Comparison and applicability" Water Research, 43(3), 2009, pp.744750.

[17] N. Ates, U. Yetis, M. Kitis "Effects of Bromide Ion and Natural Organic Matter Fractions on the Formation and Speciation of Chlorination ByProducts" Journal of Environmental Engineering, 133(10), 2007, pp.947-954.

[18] S.J. Traina, J. Novak, N.E. Smeck "An ultraviolet absorbance method of estimation of the percent aromatic carbon of humic acids" Journal of Environmental Quality, 19(1), 1990, pp. 151-153.

[19] Y.P. Chin, G. Aiken, E. O'Loughlin “Molecular weight, polydispersity, and spectroscopic properties of aquatic humic substances" Envorimental Science \& technology, 28(11), 1994, pp.1853-1858. 